\title{
Biosynthesis and Characterization of Silica Nanoparticles from Rice (Oryza sativa L.) Husk
}

\author{
Nita Babaso Patil ${ }^{1}$, H. Sharanagouda ${ }^{1}$, S.R. Doddagoudar ${ }^{2}$, \\ C.T. Ramachandra ${ }^{3}$ and K.T. Ramappa ${ }^{1}$ \\ ${ }^{1}$ Department of Processing and Food Engineering, ${ }^{2}$ Department of Seed Science and \\ Technology, University of Agricultural Sciences, Raichur- 584104 (Karnataka), India \\ ${ }^{3}$ Department of Agricultural Engineering, College of Agriculture, GKVK, \\ Bengaluru-560065 (Karnataka), India \\ *Corresponding author
}

\section{A B S T R A C T}

\section{Keywords}

Rice husk, Silica nanoparticles, FTIR SEM and XRD.

Article Info

Accepted:

17 November 2018

Available Online:

10 December 2018
Silica nanoparticles were synthesized efficiently and effectively from rice husk and characterized by various analytical techniques. The highest percentage $(89.28 \pm 0.03 \%)$ yield of silica synthesized from rice husk ash burnt at $700{ }^{\circ} \mathrm{C}$ for $2 \mathrm{~h}$. Dynamic light scattering analysis data of silica nanoparticles (SNPs) showed that the average particles diameter $93.14 \mathrm{~nm}$ with hydrophilic nature. The UV-Visible spectrum Si-O-Si bond confirming the presence of silica nanoparticles the presence of silica nanoparticles. FT-IR data revealed the presence of hydrogen bonded silanol and siloxane groups in SNPs, XRD pattern revealed amorphous form. SEM analysis data showed that uniformly distributed silica nanoparticles were in the agglomerated form with spherical shape. The use of rice husk as source of SNPs has both positive environmental and economic impact through the use of an abundant low-value agricultural by-product that can alleviate waste disposal problems.

\section{Introduction}

Agriculture is the backbone of India, with more than 60 per cent of the population relies on it for their livelihood. Science and technology played major role in increasing agricultural productivity. Among the latest line of technological innovations in the field of agriculture, nanotechnology occupies a distinguished position in remodelling agriculture and food production to fulfil the demands in an efficient and cost effective way. Nanotechnology in the field of agriculture focuses currently on target farming that involves the use of nanoparticles with unique properties to boost crop productivity. The aim of the use of nanomaterials in the field of agriculture is to improve the efficiency and sustainability of agricultural practices by putting less input and generating less waste than conventional products and approaches (Mousavi and Rezaei, 2011). The increased surfaces of nanoparticles are responsible for their different chemical, optical, mechanical, 
magnetic properties as compared to bulk materials (Mazur, 2004). Physical and chemical methods of synthesis of nanoparticles (NPs) are expensive, time consuming, labour intensive and also requires more energy. These methods are potentially hazardous to the environment and living organisms due to use of toxic reducing and stabilizing agents (Mittal et al., 2013). Therefore, there is a need to develop cost effective, non-toxic and eco-friendly method for synthesis of nanoparticles. Biosynthesis involves using an environment friendly green chemistry based approach that employs unicellular and multicellular biological entities such as actinomycetes, bacteria, fungi, plants, viruses and yeast (Vithiya and Sen, 2011). Mahgoub and Samaras (2014) reported that bio-waste materials such as cow dung ash, corn cob ash, mango stone ash, lemon peel, pomegranate peel, orange peel and rice husk ash are eco-friendly to produce typical nanoparticles with well defined chemical composition, size, and morphology.

Globally, approximately 600 million tonnes of paddy are produced each year. India stands second with a production of 120 million tonnes of paddy every year. An average 20 per cent paddy gives around 24 million tonnes of rice husk and 4.4 million tonnes of rice husk ash (Manore et al., 2016), which is great source of silica. With such a large availability of rice husk, it becomes economical to use as a source for more commercial applications. Presently, no commercial value in RH itself, usually it ends up being burned in open spaces, thus causing environmental hazards and disposal problems (Rafiee et al., 2012).

Silica nanoparticles (SNPs) have gained a greater attention because of its highly reactive surface area to volume ratio, chemical and physical stability, low toxicity and straight forward surface chemistry (Ghorbani et al., 2015). It is frequently used in industrial manufacturing, packaging, ceramic and synthesis of high molecule composites material, drug delivery, cancer therapy, disease labelling, biosensor, food and agriculture (Kasaai, 2015). Therefore, it is need of hour to develop an economically viable method to synthesize the silica nanoparticles from rice husk.

The characterization of nanoparticles is significant to appreciate and control nanoparticles synthesis and their applications. It is executed using a range of diverse techniques like scanning electron microscopy (SEM), Fourier transform infrared spectroscopy (FT-IR), dynamic light scattering (DLS), X-ray diffractometry (XRD) and UV-visible spectroscopy (UV-Vis). These techniques are helpful to resolve diverse parameters such as morphology, particle size, shape, crystallinity and surface area (Ingale and Chaudhari, 2013). The use of rice husk as source of SNPs has both positive environmental and economic impact through the use of an abundant low-value agricultural by-product that can alleviate waste disposal problems.

\section{Materials and Methods}

\section{Washing, acid treatment and thermal treatment of rice husk}

Rice husk was washed thoroughly with potable water to remove the soluble particles, dust and other contaminants. The cleaned rice husk was dried in a hot air oven (Kadavil Electro Mechanical Industries, KOMS. 6FD, India) at $110^{\circ} \mathrm{C}$ for $24 \mathrm{~h}$. The dried rice husk was refluxed with an acidic solution of $1 \mathrm{~N}$ $\mathrm{HCl}$ at $85^{\circ} \mathrm{C}$. The sample was cooled at room temperature and kept intact for about $24 \mathrm{~h}$. Then the sample was decanted and thoroughly washed with warm distilled water until the rinse became free from acid. The wet refluxed rice husk was subsequently dried in hot air 
oven at $110{ }^{\circ} \mathrm{C}$ for $24 \mathrm{~h}$. The dried rice husk was subjected to heat treatment in muffle furnace (Macro Scientific Works Pvt. Ltd., MSW-251, India) at $700{ }^{\circ} \mathrm{C}$ for $2 \mathrm{~h}$ to obtain the ash.

\section{Extraction of silica}

A sample of $20 \mathrm{~g}$ ash was stirred in a $160 \mathrm{ml}$ of $2.5 \mathrm{M} \mathrm{NaOH}$ solution. The solution was heated in a covered beaker at $90{ }^{\circ} \mathrm{C}$ for $3 \mathrm{~h}$ by stirring constantly and filtered through filter paper. The obtained viscous, transparent and colourless filtrate solution was allowed to cool at room temperature and $10 \mathrm{M}$ of $\mathrm{H}_{2} \mathrm{SO}_{4}$ was then added under constant stirring at controlled conditions until it reached to $\mathrm{pH} 2$, then $\mathrm{NH}_{4} \mathrm{OH}$ was used to adjust $\mathrm{pH}$ level up to 8.5 and was allowed to stand at room temperature for $3 \mathrm{~h}$. White silica participate was washed repeatedly with the distilled water until the filtrate was completely free from alkali (Rafiee et al., 2012). The silica was dried in hot air oven at $105{ }^{\circ} \mathrm{C}$ temperature at for $24 \mathrm{~h}$.

\section{Preparation of nanosilica powder}

Silica nanoparticles were prepared by using refluxing technique of the above extracted silica with $6 \mathrm{M}$ of $\mathrm{HCl}$ at $85{ }^{\circ} \mathrm{C}$ for $4 \mathrm{~h}$ and washed repeatedly using distilled water to make it acid free. Then it was dissolved in 2.5 $\mathrm{M}$ of $\mathrm{NaOH}$ by continuous stirring and sulphuric acid $\left(\mathrm{H}_{2} \mathrm{SO}_{4}\right)$ was added until it reached to $\mathrm{pH} 8$. The precipitated silica was washed repeatedly with warm distilled water to make it alkali free and then dried in the hot air oven at $50{ }^{\circ} \mathrm{C}$ for $48 \mathrm{~h}$ (Rafiee et al., 2012).

\section{Characterization of biosynthesized silica nanoparticles}

Biosynthesized silica nanoparticles were subjected to characterization for identification of its size, morphology and functional group.

\section{Particle size analysis using Zetasizer}

Zetasizer (Malvern, ZETA Sizer, nano383 issue 5.0, England) was used (dynamic light scattering) to study the average particle diameter (nm) of SNPs. SNPs and ethanol suspension solution was sonicated at $25{ }^{\circ} \mathrm{C}$ using the digital ultrasonication bath (Labman Scientific Instruments, LMUC-2.8L, India) for $15 \mathrm{~min}$. After sonication, the sample was centrifuged using high speed centrifuge (MPW Med. Instruments, MPW-350R, Poland) at $10000 \mathrm{rpm}$ for $10 \mathrm{~min}$. The prepared sample of SNPs suspension filled in disposable cuvette up to $34^{\text {th }}$ of volume and cuvette was placed in dynamic light scattering chamber. The average particle diameter (nm) was recorded from size distribution by intensity graph (Das et al., 2014).

\section{Absorbance analysis using UV-Visible spectrophotometer}

Silica nanoparticles were characterized by using UV- Visible spectrophotometer (Perkin Elmer, Lamda 35, Germany). The sample was prepared by diluting of $30 \mathrm{mg}$ of silica nanoparticles into $5 \mathrm{ml}$ ethanol and ethanol was used as reference in quartz cuvette $(1 \mathrm{~cm}$ path length). The absorbance of the sample recorded in wavelength ranged between 300$650 \mathrm{~nm}$ (Djangang et al., 2015). The amount of the radiation absorbed at each wavelength was recorded. The absorbance was plotted against wavelength to obtain the spectrum. From the graph, the wavelength $\left(\lambda_{\max }\right)$ was recorded at maximum absorbance.

\section{Functional groups analysis using Fourier Transform Infrared Spectroscope (FT-IR)}

Fourier transform infrared (Shimadzu, FTIR8400S, Japan) spectra was obtained on a Vertex 70 spectrometer equipped with a digital detector via the conventional potassium bromide $(\mathrm{KBr})$ pellet method. The sample of 
$0.1 \%$ was mixed with $250 \mathrm{mg}$ of potassium bromide powder. The material was finally ground using pestle and mortar. The ground sample was put into pellet forming die to form pellet size of $13 \mathrm{~mm}$. Then the pellet was placed on sample holder and subjected to scan in transmission mode with $4 \mathrm{~cm}^{-1}$ resolution at the range of $4000-450 \mathrm{~cm}^{-1}$ (Mourhly et al., 2015).

\section{Phase identification using X-Ray Diffraction (XRD)}

X-ray diffraction (Theta-theta type X-ray diffractometer, Rigaku corporation, Japan) pattern of silica nanoparticles was recorded in the high angle of 2 theta range $\left(5-70^{\circ}\right)$. Silica nanoparticles $(\sim 1 \mathrm{~g})$ were placed uniformly spread on glass sample holder and placed in scanner chamber. The set scan speed and step size $0.3 \% \mathrm{~min}$ and $0.001 \mathrm{~s}$, respectively were fixed (Djangang et al., 2015).

\section{Surface morphology analysis using} Scanning Electron Microscope (SEM)

The morphological features of silica nanoparticles were studied by using SEM (Carl Zeiss Microscopy, EVO 10, Germany). The aluminium stub $(\sim 1 \mathrm{~cm}$ dia. $)$ was employed on sample holder and cleaned to remove surface oils or dirt by using acetone and blowing with compressed gas. The double coated conductive carbon tape was used as adhesives and pasted on stub. Thin layer of dried sample $(\sim 0.2 \mathrm{mg})$ placed on adhesive surface, then it was coated with palladium to make the samples conductive using sputter coater (Quorum technologies, OM-SC7620, United Kingdom) for about 90 s. Sample holder was removed from the sputter coater and placed in vacuum chamber of SEM and magnification was (1 to 30,000 times) carried out to get clear morphology of silica nanoparticles at the accelerating voltage of 1 to $30 \mathrm{kV}$ with working distance of the sample at $10 \mathrm{~mm}$ (Haq et al., 2014).

\section{Results and Discussion}

\section{Biosynthesis of silica nanoparticles}

In order to obtain maximum recovery of silica from the RHA, silica was synthesized at optimized conditions as per past research. Washing of rice husk (RH) with potable water results clean $\mathrm{RH}$ with removal of the soluble particles, dust and other contaminants present, whereby the heavy impurities such as sand and dirt also removed. During refluxing of dried $\mathrm{RH}$ with $1 \mathrm{~N} \mathrm{HCl}$, the original yellow colour of RH was changed to brown colour on increasing the time of digestion. The metallic ingredients have a substantial effect on the quality of silica from $\mathrm{RH}$, which is mainly potassium that causes surface melting and accelerates the crystallization of amorphous silica and carbon fixation in rice husk ash. Also, a strong interaction occurs between the metallic ions and silica which leads to a considerable decrease in the surface area. Therefore, it is preferable to treat $\mathrm{RH}$ with an optimized acidic solution such as $1 \mathrm{~N}$ of $\mathrm{HCl}$ to effectively diminish impurities and to obtain highly purified silica powder (Carneiro et al., 2015; Ghorbani et al., 2015). The change in colour during digestion is also remarkable. The original yellowish and light yellow colour of the rice husk changed to brown colour on increasing the time of digestion this happens probably due to chemical reaction between acid and metals.

The white colour amorphous rice husk ash (RHA) was obtained from burning of dried refluxed $\mathrm{RH}$ in muffle furnace at $700{ }^{\circ} \mathrm{C}$ for 2 $h$, it contains less quantity of unburned carbon resides. At the dissolution stage sodium hydroxide reacts with silica and formed sodium silicate Eq. (1). The obtained filtrate of sodium silicate solution was transparent, colourless and viscous.

$$
\begin{aligned}
& \mathrm{SiO}_{2} \text { (Ash) }+2 \mathrm{NaOH}_{\text {(Caustic soda) }} \rightarrow \mathrm{Na}_{2} \mathrm{SiO}_{3} \\
& \text { (Sodium silicate) }+\mathrm{H}_{2} \mathrm{O}_{\text {(Water) }} \ldots \text { (1) }
\end{aligned}
$$


The silica particles were generated from the solution by adding sulphuric acid as catalyst. The acidic condition of $\mathrm{pH} 2$ indicates, approximately the complete precipitation of silica from sodium silicate by the following reaction.

$\mathrm{Na}_{2} \mathrm{SiO}_{3}$ (Sodium silicate) $+\mathrm{H}_{2} \mathrm{SO}_{4} \rightarrow \mathrm{SiO}_{2}$ (Silica) + $\mathrm{Na}_{2} \mathrm{SO}_{4}$ (Sodium sulfate) $+\mathrm{H}_{2} \mathrm{O}$ (Water) $\ldots$ (2)

RHA sample after being extracted by $2.5 \mathrm{~N}$ of sodium hydroxide $(\mathrm{NaOH})$ recorded the silica yield $89.28 \pm 0.03 \%$. The metallic impurities of extracted silica were removed by refluxing using $6 \mathrm{M} \mathrm{HCl}$ and dissolved in $2.5 \mathrm{~N} \mathrm{NaOH}$ while continuously stirring with magnetic stirrer and $\mathrm{H}_{2} \mathrm{SO}_{4}$ used for predicated nanosilica. Finally the amorphous pure white nanosilica was obtained by drying in the hot air oven at $50{ }^{\circ} \mathrm{C}$ for $48 \mathrm{~h}$. Haq et al., (2014) reported that, the amount of precipitated silica was dependent upon the applied processing parameters, such as concentration of sodium hydroxide, extraction time, solid to solution ratio, etc. The present finding is in good conformity with the results of Thuadaij and Nuntiya (2008) and Indhumathi et al., (2011) who reported that the concentration of $\mathrm{NaOH}$ had strong effect on the dissolution, particle size and surface area of silica and also remove some impurities which were not dissolved from the main product. Highest percent yield of silica $(90.3 \%)$ were extracted using $2.5 \mathrm{~N}$ of $\mathrm{NaOH}$ treatments. Also, Yuvakkumar et al., (2014) found that $2.5 \mathrm{~N}$ of $\mathrm{NaOH}$ treatment was best suited for the synthesis of high purity nanosilica powders with a low synthesis technique.

According to Rafiee et al., (2012) pH plays an important role during silica synthesis, a low silicate concentration ( $\mathrm{pH}$ less than 8), $\mathrm{Si}(\mathrm{OH})_{4}$ is the dominant species in its aqueous solution. At higher concentrations $(\mathrm{pH}$ greater than 8), the silanols, $\mathrm{Si}(\mathrm{OH})$ groups, spontaneously polymerize to yield higher oligomers linked by a disiloxy bond. This reaction is most favourable when one of the silanols is deprotonated to a $\mathrm{Si}-\mathrm{O}$ group. These oligomers grow into colloid sized silica particles in which larger particles grow at the expense of smaller ones. At a higher $\mathrm{pH}$ (greater than 8), however, the much more concentrated silicate solution is stable. This is because disiloxy bonds undergo nucleophilic attacks by $\mathrm{OH}$ via a five coordinated intermediate. The magnetic stirring of $3 \mathrm{~h}$, during dissolution of $2.5 \mathrm{M}$ of $\mathrm{NaOH}$ and silica, reduce the size of extracted silica, which converts into silica nanoparticles.

Fig.1 Average particle diameter of silica nanoparticles

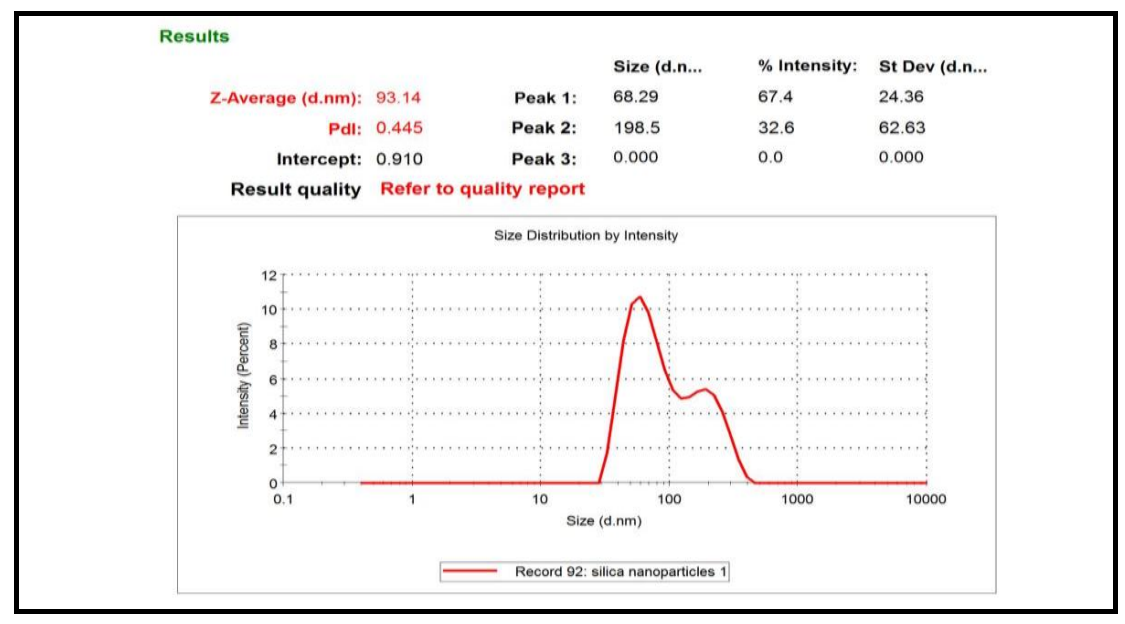


Fig.2 UV-Visible spectrum of silica nanoparticles

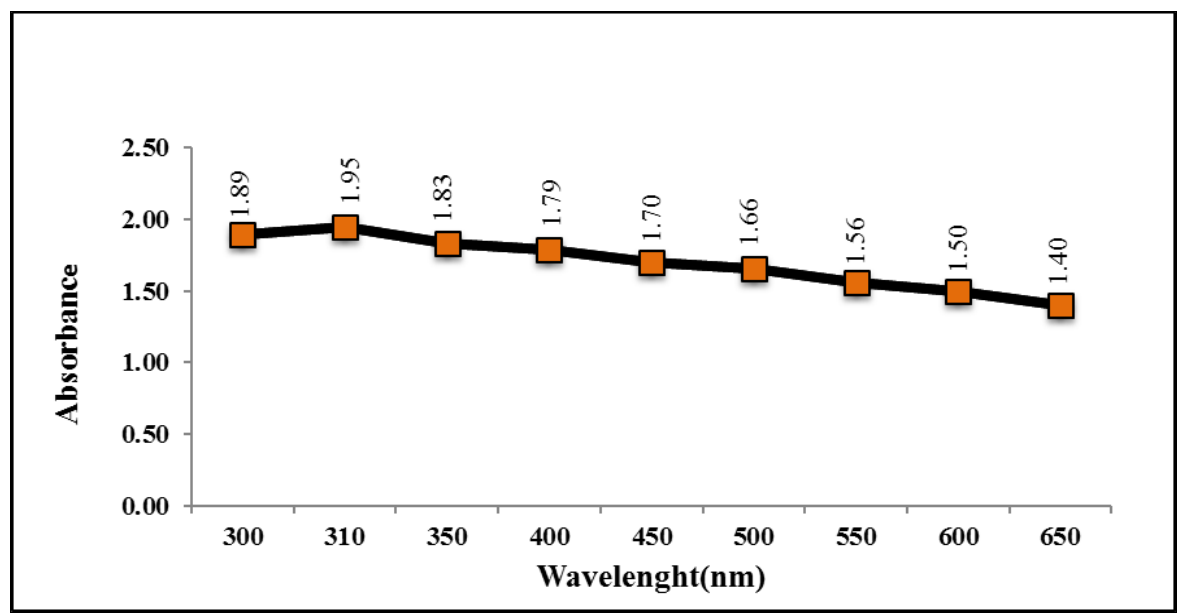

Fig.3 FT-IR spectra of silica nanoparticles

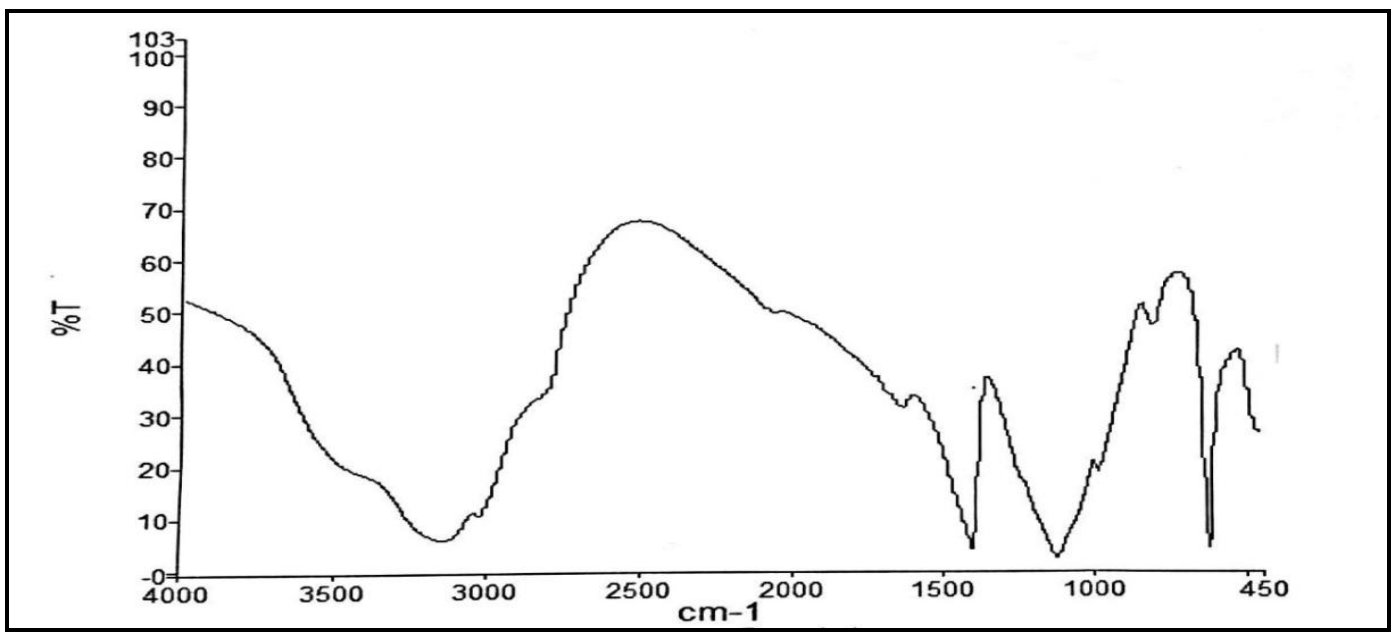

Fig.4 XRD pattern of silica nanoparticles

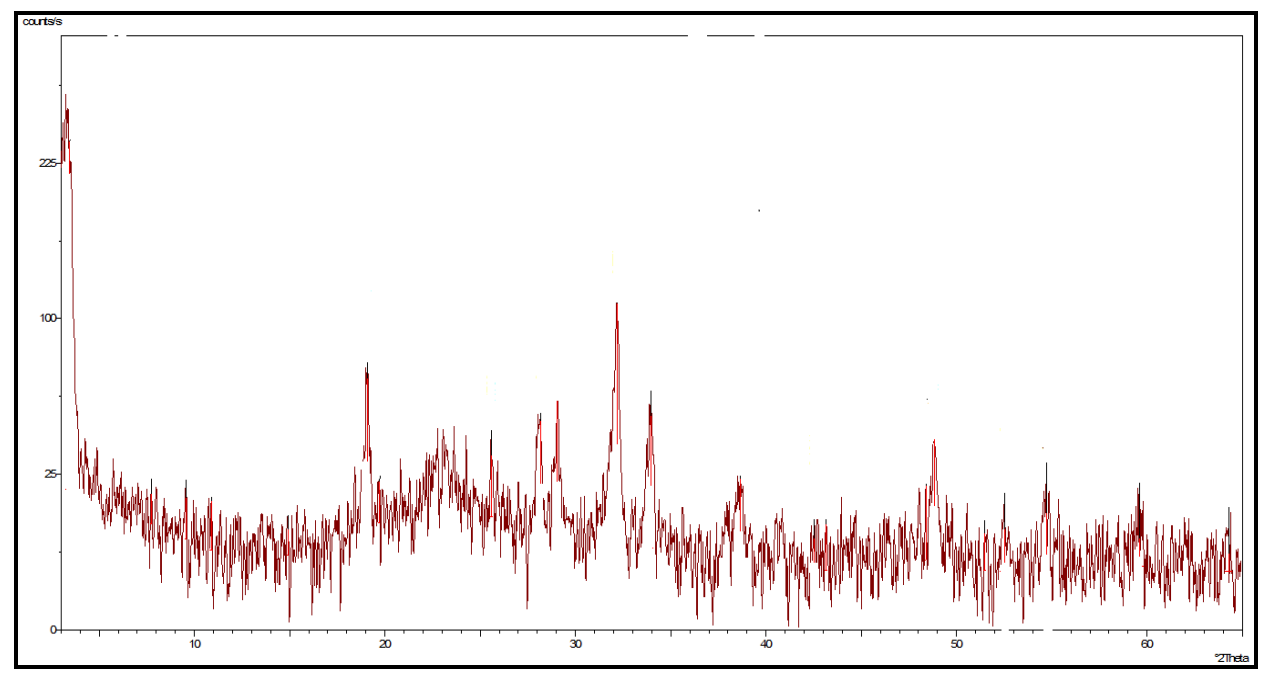


Fig.5 SEM image of silica nanoparticles

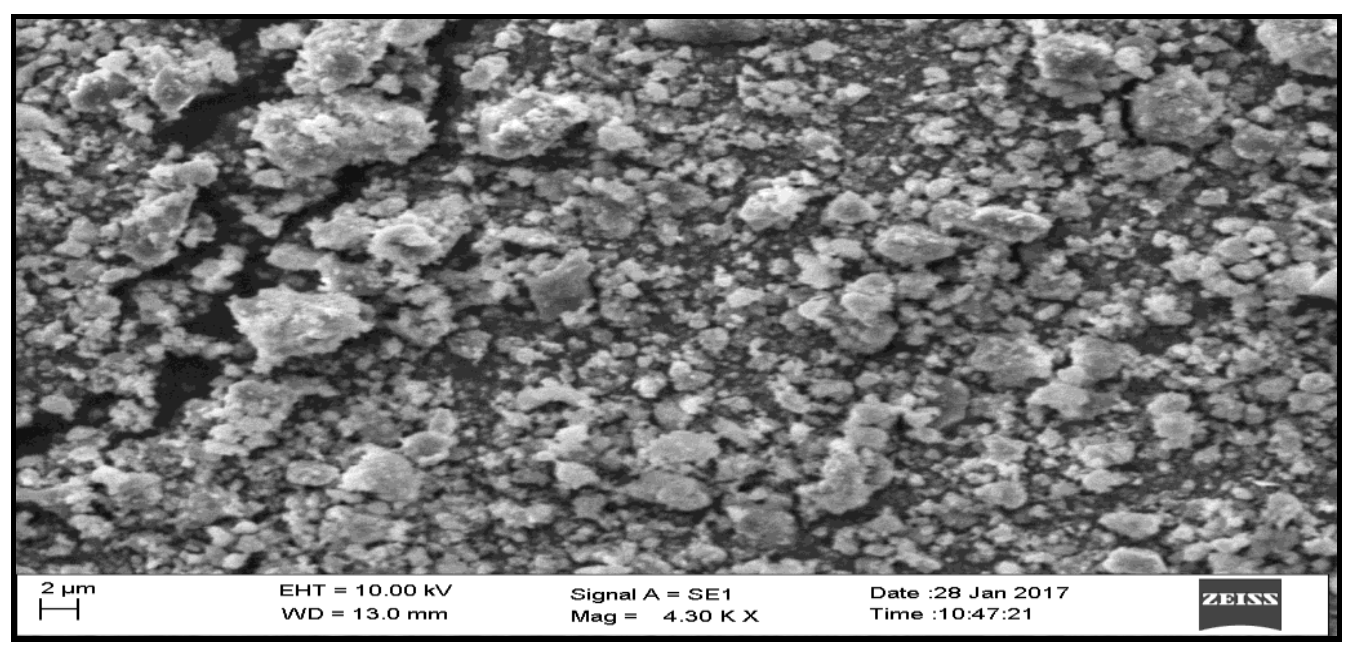

\section{Characterization of biosynthesized silica nanoparticles}

The results of Zetasizer revaluated that average particle diameter of silica nanoparticles was $93.14 \mathrm{~nm}$ as shown in Figure 1.

The UV-Visible spectrum of SNPs recorded maximum absorption band edge of $310 \mathrm{~nm}$ in 1.95 absorbance as shown in Figure 2. These optical features are similar to those obtained in previous reports and attributed to $\mathrm{Si}-\mathrm{O}-\mathrm{Si}$ bond confirming the presence of silica nanoparticles (Vaccaro et al., 2013; Djangang et al., 2015).

FT-IR spectra of SNPs as shown Figure 3 revealed that, the broad band between 2800 and $3750 \mathrm{~cm}^{-1}$ was due to silinol $\mathrm{OH}$ groups and adsorbed water and 2100 to $2300 \mathrm{~m}^{-1}$ was due to silane group $\mathrm{Si}-\mathrm{H}$. The predominant absorbance peak at $1320 \mathrm{~cm}^{-1}$ was due to siloxane bonds ( $\mathrm{Si}-\mathrm{OSi}$ ), the peaks between 1200 and $700 \mathrm{~cm}^{-1}$ were attributed to vibration modes of the gel network. IR spectrum was clearly shown the pure silica. Results are in good agreement with findings of Indhumathi et al., (2011) and Balamurugan and Saravanan (2012).
X-ray powder diffraction pattern of the biosynthesized silica nanoparticles showed broad halo at of absorption about $2 \theta=15-25$ region, which confirms the amorphous structure of silica nanoparticles in the sample. Figure 4 shows that, the X-ray diffraction pattern of silica nanoparticles which is characterized by a broad halo band of absorbance at about $2 \theta=15-25^{\circ}$ region which confirms the amorphous structure of silica nanoparticles, similar results were recorded by Djangang et al., (2015) who reported amorphous nature of silica nanoparticles from rice husk.

SEM analysis data as shown in Figure 5 showed that uniformly distributed silica nanoparticles were in the agglomerated form with spherical shape.

In conclusion, biosynthesis of silica nanoparticles from rice husk involves as an environment friendly green synthesis approach. The use of rice husk as source of SNPs has both positive environmental and economic impact through the use of an abundant low-value agricultural by-product that can alleviate waste disposal problems. Biosynthesized silica nanoparticles can be used in various purposes in industry and agriculture. 


\section{Acknowledgement}

The authors thanks to the University of Agricultural Sciences, Centre for Nanotechnology, Department of Processing and Food Engineering and Department of Seed Science and Technology, Raichur, Karnataka, India to provide the facility to carry out the experimental work and also thanks to Indian Council of Agriculture Research (ICAR) for the financial support under National Talent Scholarship during research work.

\section{References}

Balamurugan, M. and Saravanan, S., 2012, Producing nanosilica from sorghum vulgare seed heads. Powder. Technol., 224(2): 345350 .

Balamurugan, M. and Saravanan, S., 2012, Producing nanosilica from sorghum vulgare seed heads. Powder. Technol., 224(2): 345350 .

Carneiro, M. E., Magalhaes, W. L. E., Muniz, G. I. B., Nisgoski, S. and Satyanarayana, K. G., 2015, Preparation and characterization of nano silica from Equisetum arvenses. $J$. Bioproces. Biotech., 5(2): 1-7.

Das, D., Yang, Y., O'Brien, J. S., Breznan, D., Nimesh, S., Bernatchez, S., Hill, M., Sayari, A., Vincent, R. and Kumarathasan, P., 2014, Synthesis and physicochemical characterization of mesoporous $\mathrm{SiO}_{2}$ nanoparticles. J. Nanomater., 62(6)11-12.

Djangang, C, N., Mlowe, S., Njopwouo, D. and Revaprasadu, N., 2015, One-step synthesis of silica nanoparticles by thermolysis of rice husk ash using non toxic chemicals ethanol and polyethylene glycol. J. Applicable. Chem., 4(4): 1218-1226.

Ghorbani F., Sanati, A. M. and Maleki, M., 2015, Production of silica nanoparticles from rice husk as agricultural waste by environmental friendly technique. Environmental Studies of Persian Gulf., 2(1): 56-65.

Ghorbani F., Sanati, A. M. and Maleki, M., 2015, Production of silica nanoparticles from rice husk as agricultural waste by environmental friendly technique. Environmental Studies of Persian Gulf., 2(1): 56-65.

Haq, I. U., Akhtar, K. and Malik, A., 2014, Effect of experimental variables on the extraction of silica from the rice husk ash. J. Chem. Soc. Pak., 36(3): 382-387

Indhumathi, P., Syed, S. S. P. and Saraswathy, C. P., 2011, Synthesis and characterization of nano silica from the pods of delonixregia ash. Int. J. Adv. Engr. Tech., 2(4): 421-426.

Kasaai, M.R., 2015. Nanosized particles of silica and its derivatives for applications in various branches of food and nutrition sectors. J. Nanotech. 2015.

Mahgoub, S. and Samaras, P., 2014, Nanoparticles from biowastes and microbes: focus on role in water purification and food preservation. $2^{\text {nd }}$ International conference on sustainable solid waste managements, Greece, Athens.

Manore, S. S. Chaudhari, G. and Sane, S., 2016, Electricity from rice husk. Int. J. Recent. Innov. Trends. Comput. Commun., 4 (9):1619.

Mazur, M., 2004, Electrochemically prepared silver nanoflakes and nanowires, Electrochem. Commun., 6(4): 400-403.

Mittal, A. M., Chisti, Y. and Banerjee, Y. A., 2013, Synthesis of metallic nanoparticles using plant extracts. Biotech. Adv., 31(2): 346-356.

Mourhly, A., Khachani, M., Hamidi, A.E., Kacimi, M., Halim, M. and Arsalane, S., 2015, The synthesis and characterization of low-cost mesoporous silica $\left(\mathrm{SiO}_{2}\right)$ from local pumice rock. Nanomater. Nanotechno., 3(6): 30-35.

Mousavi, S. R. and Rezaei, M., 2011, Nanotechnology in agriculture and food production. J. Appl. Environ. Biol. Sci., 1(10):414-419.

Rafiee, E., Shahebrahimi, S., Feyzi, M. and Shaterzadeh, M., 2012, Optimization of and characterization of nanosilica produced from rice husk (common waste material). Int. Nano. Lett., 2(29): 1-8.

Spallino, L., Agnello, S., Buscarino, G. and Cannas, M., 2013, Defect-related visible luminescence of silica nanoparticles. Phys. Status. Solidi. C., 10(4): 658-661.

Thuadaij, N. and Nuntiya, A., 2008, Preparation 
of nanosilica powder from rice husk ash by precipitation method. Chiang. Mai J. Sci., 35(1): 206-211.

Vithiya, K. and Sen, S., 2011, Biosynthesis of nanoparticles. Int. J. Pharma. Sci., 2(11): 2781-2785.
Yuvakkumar, R., Elango, V., Rajendran, V. and Kannan, N., 2014, High-purity nano silica powder from rice husk using a simple chemical method. J. Exp. Nanosci., 9(3): 272-281.

\section{How to cite this article:}

Nita Babaso Patil, H. Sharanagouda, S.R. Doddagoudar, C.T. Ramachandra and Ramappa,

K.T. 2018. Biosynthesis and Characterization of Silica Nanoparticles from Rice (Oryza sativa L.) Husk. Int.J.Curr.Microbiol.App.Sci. 7(12): 2298-2306.

doi: https://doi.org/10.20546/ijcmas.2018.712.261 